\title{
Integrated impact assessment of adaptive management strategies in a Dutch peatland polder
}

\author{
Henk van Hardeveld ${ }^{1,2}$, Harm de Jong ${ }^{3}$, Maxim Knepflé ${ }^{4}$, Thijs de Lange ${ }^{3}$, Paul Schot ${ }^{1}$, Bas Spanjers ${ }^{5}$, \\ and Sven Teurlincx ${ }^{6}$ \\ ${ }^{1}$ Copernicus Institute of Sustainable Development, Utrecht University, Utrecht, the Netherlands \\ ${ }^{2}$ Waternet, Amsterdam, the Netherlands \\ ${ }^{3}$ Hoogheemraadschap De Stichtse Rijnlanden, Houten, the Netherlands \\ ${ }^{4}$ Tygron, Den Haag, the Netherlands \\ ${ }^{5}$ Brandenburg State Office of Environment, Potsdam, Germany \\ ${ }^{6}$ Netherlands Institute of Ecology NIOO-KNAW, Wageningen, the Netherlands \\ Correspondence: Henk van Hardeveld (henk.van.hardeveld@waternet.nl)
}

Published: 22 April 2020

\begin{abstract}
To achieve a more sustainable management of the subsiding Dutch peatlands, adaptations such as progressively higher surface water levels, pressurized field drains and a transition from dairy farming to paludiculture are considered. However, a clear understanding of implementation pathways for adaptive management strategies is lacking. Therefore, we used the RE:PEAT tool to elucidate the short-term and long-term impacts during 2025-2100 of two adaptive management strategies in Polder Zegveld and how to fairly distribute the costs and benefits of these strategies among the stakeholder groups. The strategies resulted in marked differences in soil subsidence and temporal trends in societal costs and benefits that affected stakeholders unequally. The adaptations were shown to reduce soil subsidence and enhance the sustainability of peatland management. We explored several options for a collective implementation of the adaptative management strategies. In addition, we discuss several ideas to further capitalize on the potential of the RE:PEAT tool to support peatland management. Currently, we are developing additional features that enable high spatio-temporal resolution simulations of the integrated dynamics of the surface water system, the shallow groundwater system, rainfall-runoff processes and solute transport. In combination with the PCDitch model, this will also enable detailed ecological assessments. This will pave the way for implementation pathways for adaptive management strategies that will contribute to a more sustainable peatland management.
\end{abstract}

\section{Introduction}

Unsustainable human exploitation has resulted in the degradation of peatlands worldwide (Joosten and Clarke, 2002). The drainage of peatlands results in short-term benefits such as agricultural production, but also causes long-term problems such as soil subsidence, emission of greenhouse gasses, loss of biodiversity, and increasing management costs (Bragg and Lindsay, 2003; Van Hardeveld et al., 2018). To arrest and reverse the unsustainable exploitation of peatlands, management strategies must address the complex interrelations be- tween their biophysical dynamics and their socio-economic context.

The Dutch peatlands are a prime example of drained peatlands which are faced with multiple long-term problems and the challenge of implementing a more sustainable management. In response to this complex challenge, experimental collaborate adaptive management strategies are increasingly put into practice. The building blocks for these experiments reflect wetter conditions which can preserve the peat, such as (a) increasingly higher surface water levels, (b) novel applications of field drains, and (c) a transition in land use from dairy farming to paludiculture, i.e., the cultivation of species 
such as Common reed (Phragmites) and Bulrush (Typha) in permanent wet conditions. Although these experiments increase our knowledge of the effects of these adaptations, a clear understanding of implementation pathways is still lacking. The design of implementation pathways requires an integrated assessment of time-and-place specific peatland conditions and feasible management options with a fair distribution of costs and benefits.

The RE:PEAT tool (Van Hardeveld et al., 2019) is especially suited to deal with complex challenges like this. It simulates time-and-place specific effects of interventions and provides support for the negotiation processes needed to design pathways towards sustainable peatland management. In this paper, the RE:PEAT tool is used to contribute to our understanding of feasible implementation pathways for adaptive peatland management. The illustrative context for this endeavour is Polder Zegveld, a Dutch peatland polder of $18 \mathrm{~km}^{2}$ located between the cities of Amsterdam, Rotterdam and Utrecht. The questions we seek to answer are: (1) What are the major short-term and long-term impacts of adaptive management strategies? (2) How can the costs and benefits of the management strategies be fairly distributed among the stakeholder groups?

\section{Methods}

The RE:PEAT tool is embedded in the Tygron Geodesign Platform (TGP), an interactive software platform for 3D modelling of spatial development projects. The TGP integrates a broad range of spatial data and allows the user to combine these data with practical and scientific knowledge. For example, RE:PEAT combines spatial explicit data on soil properties and groundwater tables with an empirical soil subsidence equation (Van den Akker et al., 2008). As a result, spatially and temporally explicit assessments can be made of the integrated dynamics of water management and soil subsidence, including a broad range of societal costs and benefits. See Van Hardeveld et al. (2019) for further details.

In this research, we assessed the following impacts of adaptive management strategies: (a) soil subsidence, (b) management cost of the water system, (c) management costs of the infrastructure of roads and sewers, (d) damage to the foundations of real estate, (e) Net Value Added of agriculture, (f) terrestrial emission of greenhouse gasses, and (g) expected dominant type of vegetation in the drainage ditches. Regarding impacts (b)-(e), we used empirical data provided by the water authority, the municipality, and the local farmers to calibrate the simulation parameters of RE:PEAT to the local conditions. Regarding the emission of greenhouse gasses, we used the equations of Van den Akker et al. (2008) to assess the emission of $\mathrm{CO}_{2}$ and the equations of Cauwenberg et al. (2011) to assess the emission of $\mathrm{CH}_{4}$ and $\mathrm{N}_{2} \mathrm{O}$.
We assessed the impacts in the years 2025, 2050, 2075, and 2100 of the business-as-usual strategy (1) and two adaptive peatland strategies ( 2 and 3 ):

1. Current surface water levels, which reflect the businessas-usual strategy. The surface water levels are maintained at $30-70 \mathrm{~cm}$ below the ground surface and must be lowered periodically to compensate for the soil subsidence.

2. Progressively higher water levels. The surface water levels are maintained at the current absolute level throughout time. This implies that, as soil subsidence progresses, the surface water levels will become shallower, leading to increasingly wetter conditions, and lower soil subsidence rates.

3. Progressively higher water levels with pressurized field drains. The field drains are connected to a water reservoir which regulates the pressure head in the drains. As a result, the groundwater tables are maintained at 25$45 \mathrm{~cm}$ below the ground surface.

We assumed land use would change from dairy farming to paludiculture when, due to high groundwater tables, a diminished crop yield would result in a lower Net Value Added for dairy farming than for paludiculture. Assuming the current market for dairy products would remain unchanged, we used a maximum Net Value Added of dairy farming of EUR 1518 per hectare per year. Drawing on the preliminary results of experiments with paludiculture in Germany and the Netherlands, we assumed a range of maximum Net Value Added of paludiculture of EUR 550-1550 per hectare per year. The lower boundary of the range reflects the cultivation of fodder crops, the upper boundary reflects the use of biomass from paludiculture as building material.

\section{Results}

The management strategies result in marked variations in the spatial patterns of soil subsidence, ranging from several $\mathrm{cm}$ at locations with shallow groundwater tables and/or thick clay deposits, more than $80 \mathrm{~cm}$ at locations with deeper groundwater tables and/or thin clay deposits (Fig. 1). The application of pressurized field drains effectively reduces the cumulative soil subsidence compared to the other two strategies at most locations, except the small village in the centre and several non-agricultural plots on which no field drains were installed.

The management strategies also result in marked temporal trends (Fig. 2). Compared to the business-as-usual strategy pressurized field drains will reduce soil subsidence in the short-term as well as the long-term, whereas progressively higher surface water levels will reduce soil subsidence in the long-term only (Fig. 2a). As a result, the scenario with pressurized field drains results in marked lower management costs for subsiding infrastructure of roads and sewers 


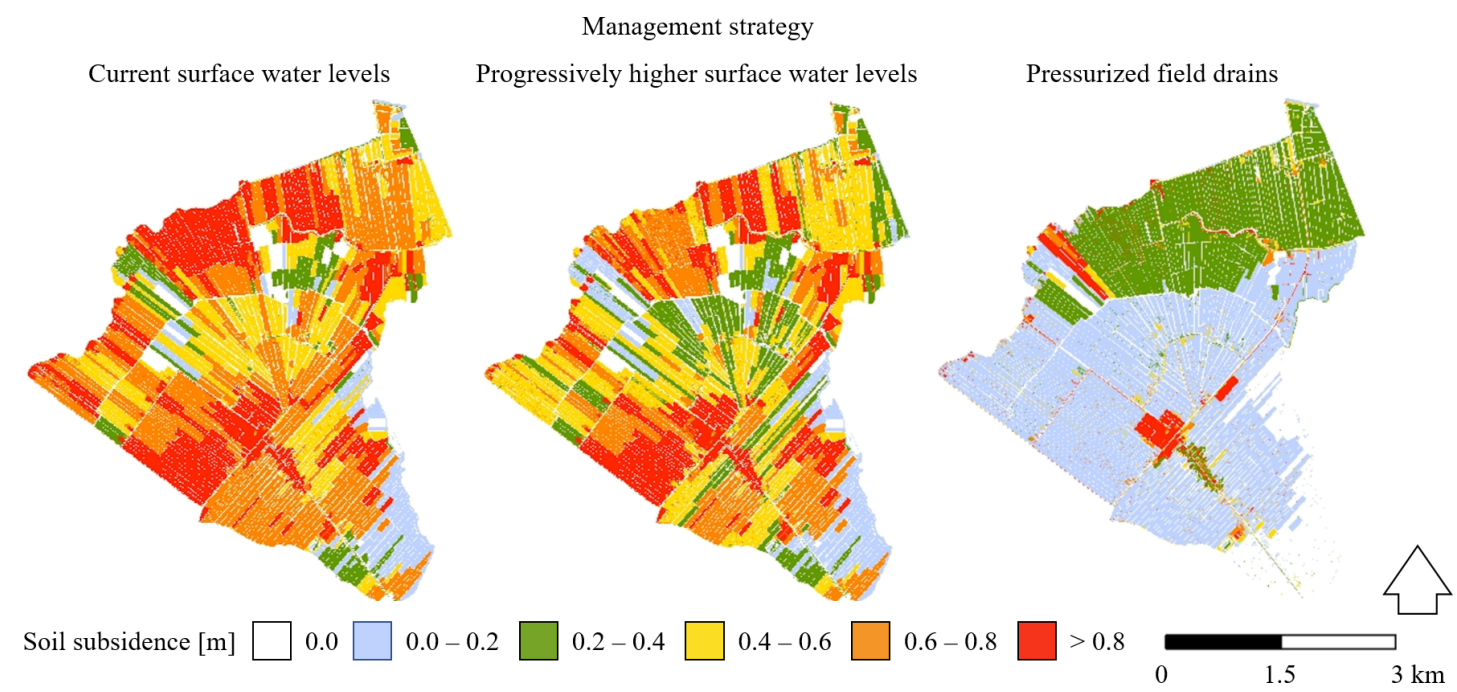

Figure 1. Cumulative soil subsidence in 2019-2100 in the research area resulting from the three management strategies.

(Fig. 2c), a higher Net Value Added for agriculture (Fig. 2e), lower emissions of greenhouse gasses (Fig. 2g), and higher percentages of ditches with good water quality, i.e., with a dominance of submerged rooted vegetation over duckweed and algae (Fig. 2h).

For all scenarios, the damage costs to real estate are markedly higher in the short-term than in the long-term (Fig. 2d) because at present, the foundations of $33 \%$ of the houses are already damaged. In the scenarios with current surface water levels (1) and pressurized field drains (3), there is little incentive for farmers to switch from dairy farming to paludiculture (Fig. 2f). In the scenario with progressively higher surface water levels (2), the Net Value Added for dairy farming will drop from EUR 919 to 558-593 per hectare in 2100. As a result, $24 \%-36 \%$ of the farmland will switch to paludiculture. This explains why the trend in Net Added Value of this scenario does not continue downwards but stabilizes at EUR 600-700 per hectare.

\section{Discussion}

\subsection{Designing sustainable pathways}

The results show that adaptative management can reduce soil subsidence and enhance the sustainability of peatland management. The remaining challenge is to distribute the costs and benefits fairly among the stakeholder groups. Regarding pressurized field drains, the annual costs of interest, depreciation, and maintenance amounts to approximately EUR 425 per hectare. Regarding progressively higher surface water levels, the implementation costs are zero, but the reduction in the agricultural Net Added Value amounts to EUR 478 per hectare per year in the long-term.

The RE:PEAT tool is especially suited for the task of brokering deals that enable a collective strategy. Interactive ap- plications of the tool with real-world stakeholders has shown that RE:PEAT enhances their understanding of peatland dynamics and simultaneously increases the cooperation among them, strengthening their resolve to collectively implement sustainable management strategies (Van Hardeveld et al., 2019).

The simulations show that several benefits result from the collective management strategies. Regarding pressurized field drains, the agricultural benefits are EUR 142-279 per hectare. In addition, the management costs of the municipality will decrease by EUR 192 per hectare. However, these benefits are overstated, because we did not assess subsidence due to compaction resulting from the added weight of roadbeds and traffic, which has a bigger impact on the management costs of the municipality than drainage-related soil subsidence. The benefits for the water authority were assessed with a higher accuracy. In the long-term, the management costs are EUR 416 per hectare lower compared to the business-as-usual scenario. However, in the short-term, the management costs of both scenarios are very similar.

Because in the short term, the sum of financial benefits is either too uncertain or too small to cover the adaptation costs, the implementation of adaptive peatland management will require additional contributions. In particular, the nonfinancial benefits of improved water quality (Fig. $2 \mathrm{~h}$ ) and reduced greenhouse gas emissions (Fig. 2g) may merit some financial contribution. For instance, a subsidy of EUR 38 per reduction of $10^{3} \mathrm{CO}_{2}$-equivalents would cover all implementation costs of pressurized field drains, whereas a compensation for the decrease in agricultural Net Added Value due to progressively higher surface water levels would require a subsidy of EUR 188 per reduction of $10^{3} \mathrm{CO}_{2}$-equivalents. 

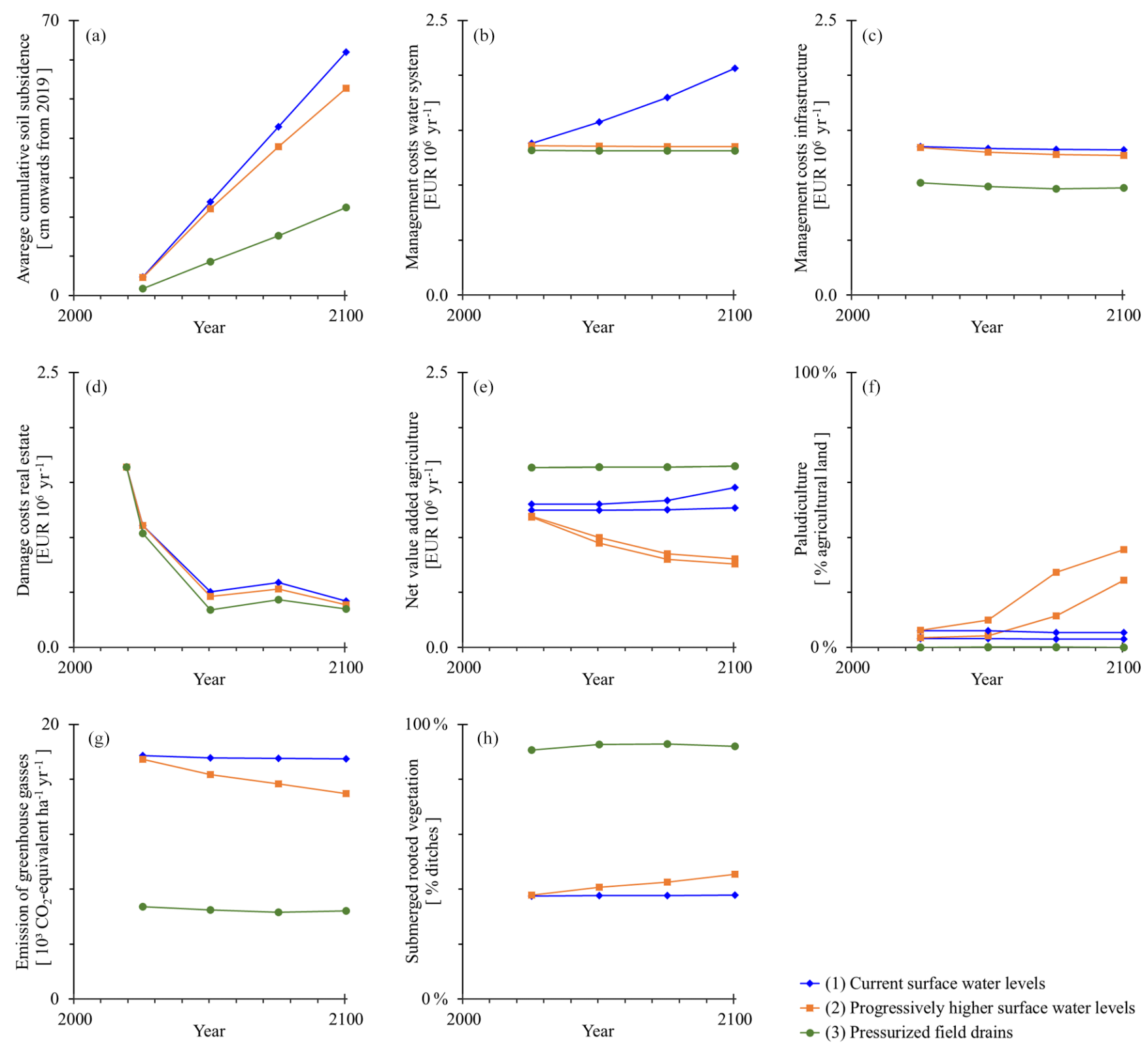

$\rightarrow$ (1) Current surface water levels

$\rightarrow$ (2) Progressively higher surface water levels

$\rightarrow$ (3) Pressurized field drains

Figure 2. Effects of the three management strategies. The upper and lower limits to the range of agricultural values (e, f) reflect the uncertainty regarding paludiculture. The uncertainty regarding dairy products is not reflected in the results (e, f).

\subsection{Towards a higher level}

Our results show that in theory, the collective stakeholder groups can design adaptive management strategies with fairly distributed costs and benefits. However, the implementation of these strategies requires more certainty regarding the effects of the adaptations. Most urgently, more certainty regarding the viability of paludiculture, i.e., empirical evidence of crop yields at a range of groundwater tables, and an economic business case of the expected Net Value Added are needed. In addition, more long-term empirical data are needed regarding the emission of greenhouse gasses from agricultural areas with paludiculture and/or pressurized field drains.

The RE:PEAT tool was shown to be well suited to support peatland management The results compared well to empirical data of management costs, agricultural Net Value Added, and soil subsidence rates in the research area. However, the assessment of water quality needs improvements. Most likely, we overestimated the improvement of water quality, because we did not adequately consider the spatial heterogeneity of hydrological discharges throughout the dense network of small ditches, nor did we consider the detailed dynamics of solute transport from the soil to the ditches and 
subsequently, from the ditches to the main pumping station of Polder Zegveld.

We are improving the water quality assessment with RE:PEAT by incorporating additional features in the TGP, which enable high resolute spatially and temporally explicit simulation of the integrated dynamics of the surface water system, the shallow groundwater system, rainfall-runoff processes and solute transport. These additions to the TGP enable the assessment of nutrient and water flows. Currently, we are linking these outputs to a set of over 1 million runs of the PCDitch model (Janse and van Puienbroek, 1998), which consists of combinations of hydraulic loading, nutrient loading, sediment type, water depth, water background extinction, water temperature, and management impacts such as mowing and dredging. The linkage with PCDitch simulates the ecological status of every water course under varying conditions. While such an implementation does not allow for full dynamically coupled calculations, it has the advantage of providing near instant feedback between the decision support system and the user.

\section{Conclusions}

Pressurized field drains will reduce soil subsidence in the short-term as well as the long-term, resulting in marked lower management costs, a higher Net Value Added for agriculture, lower emissions of greenhouse gasses, and better water quality. Progressively higher surface water levels will reduce soil subsidence in the long-term, resulting in a lower Net Value Added for dairy farming and a transition of $24 \%-$ $36 \%$ of the farmland to paludiculture.

The costs of the adaptive management strategies amount to EUR 425-478 per hectare per year in the long-term. In the short term, the financial benefits for farmers, the municipality and the water authority are too small to cover these costs. Therefore, implementation of the adaptations will only be feasible if the non-financial benefits of improved water quality and reduced greenhouse gas emissions are considered. A subsidy of EUR 38-188 per reduction of $10^{3} \mathrm{CO}_{2}$ equivalents would cover all implementation costs.

The implementation of adaptive management strategies requires more certainty regarding the effects of the adaptations and additional features of the RE:PEAT tool. This will improve decision support for peatland management and facilitate adaptive management strategies that will contribute to a more sustainable peatland management.

Data availability. The underlying research data is not publicly avaliable, because the experimental management strategies do not reflect the common policy of the regional water authority. Anyone who wishes to access the data for scientific reasons is encouraged to contact the corresponding author.
Author contributions. The method was designed by HvH, HdJ, BS and ST. HvH and HdJ conducted the analyzes with RE:PEAT. The PCDitch simulations were made by ST. The writing of the paper was a joint effort of all authors.

Competing interests. The authors declare that they have no conflict of interest.

Special issue statement. This article is part of the special issue "TISOLS: the Tenth International Symposium On Land Subsidence - living with subsidence". It is a result of the Tenth International Symposium on Land Subsidence, Delft, the Netherlands, 17-21 May 2021.

Acknowledgements. We thank Susan Graas for helping us understand the current water management practices in Polder Zegveld, Bob Brederveld for his contribution to the PCDitch simulations and Devin Galloway for his thoughtful comments which helped to improve the paper.

\section{References}

Bragg, O. and Lindsay, R. (Eds.): Strategy and Action Plan for Mire and Peatland Conservation in Central Europe, Wetlands International, Wageningen, the Netherlands, 2003.

Couwenberg, J., Thiele, A., Tanneberger, F., Augustin, J., Bärisch, S., Dubovik, D., Liashchynskaya, N., Michaelis, D., Minke, M., Skuratovich, A., and Joosten, H.: Assessing greenhouse gas emissions from peatlands using vegetation as a proxy, Hydrobiol. 674, 67-89, https://doi.org/10.1007/s10750-011-0729-x, 2011.

Janse, J. H. and van Puijenbroek, P. J. T. M.: Effects of eutrophication in drainage ditches, Environ. Pollut., 102, 547-552, https://doi.org/10.1016/S0269-7491(98)80082-1, 1998.

Joosten, H. and Clarke, D.: Wise Use of Mires and Peatlands Background and Principles Including a Framework for Decisionmaking, International Mire Conservation Group and International Peat Society, Saarijärven, Finland, 2002.

Van den Akker, J. J. H., Kuikman, P. J., de Vries, F., Hoving, I., Pleijter, M., Hendriks, R. F. A., Wolleswinkel, R. J., Simões, R. T. L., and Kwakernaak, C.: Emission of $\mathrm{CO}_{2}$ from Agricultural peat soils in the Netherlands and ways to limit this emission, in: Proceedings of the 13th International Peat Congress After Wise Use - The Future of Peatlands, Vol. 1 Oral Presentations, Tullamore, Ireland, 8-13 June 2008, edited by: Farrell, C. and Feehan, J., International Peat Society, Jyväskylä, Finland, 645-648, 2008.

Van Hardeveld, H. A., Driessen, P. P. J., Schot, P. P., and Wassen, M. J.: Supporting collaborative policy processes with a multicriteria discussion of costs and benefits: The case of soil subsidence in Dutch peatlands, Land Use Policy, 77, 425-436, https://doi.org/10.1016/j.landusepol.2018.06.002, 2018.

Van Hardeveld, H. A., Driessen, P. P. J., Schot, P. P., and Wassen, M. J.: How interactive simulations can improve the support of environmental management? Lessons from the Dutch peatlands, Environ. Model. Softw., 119, 135-146, https://doi.org/10.1016/j.envsoft.2019.06.001, 2019. 